\title{
Avaliando a Usabilidade e a Experiência de Uso de Aplicativos de Acompanhamento do Ciclo Menstrual
}

\author{
Brenno Nogueira Edney Queiroz Jêsca Nobre Maryanna Araújo Ingrid Monteiro \\ Universidade Federal do Ceará (UFC), Quixadá, Brasil \\ [brennonogueirao@, edneyqgp@, maryannadd@]gmail.com, [jescanobre@alu., ingrid@]ufc.br
}

\begin{abstract}
RESUMO
Pessoas atentas aos cuidados com a saúde aproveitam a vasta gama de dispositivos, aplicativos e sistemas disponível no mercado. As mulheres, em particular, desde muito tempo, são estimuladas a acompanhar seu ciclo menstrual, seja por meio de anotações ou memorização das datas ou observação dos sintomas corporais. Para ajudar nesta tarefa, existem vários aplicativos com esta finalidade. Neste relatório apresentamos uma avaliação da usabilidade e da experiência de uso de dois deles, Clue e Meu Calendário, por meio de questionários, diários de usuário e testes de usabilidade. Apresentamos uma comparação entre eles, além de discutir sobre os problemas encontrados e as sugestões de melhoria dadas pelos participantes do estudo.
\end{abstract}

Palavras-chave

Avaliação de aplicativos, ciclo menstrual, experiência de uso, diário de usuário.

\section{INTRODUÇÃO}

Com a correria diária e o mundo globalizado, muitas atividades foram sendo "informatizadas" para que pudessem ser realizadas de forma mais rápida e prática. Para acompanhar esse ritmo, os cuidados com a saúde também foram ganhando suas formas digitais. As lojas de aplicativos trazem categorias dedicadas a este tema, disponibilizando aplicativos diversos voltados a cuidados com a saúde e bem-estar, como controle e acompanhamento de dietas, consumo de medicamentos, práticas de exercícios físicos, entre outras atividades.

Estudos recentes têm explorado os aplicativos de cuidados com a saúde, alguns focados em concepção e desenvolvimento [3,7], outros concentrados na avaliação de uso [1,6]. Dentro deste último grupo, Roquet e Sas [6] avaliaram 16 aplicativos de meditação, usando etnografia e avaliação por especialistas. Os resultados do estudo mostraram que os aplicativos de meditação mais populares focavam em técnicas de meditação guiada, deixando em segundo plano o monitoramento do processo intrínseco de meditação e a medição da efetividade do treinamento. Já Bennett et al [1] realizaram a avaliação de um protótipo de

Permission to make digital or hard copies of all or part of this work for personal or classroom use is granted without fee provided that copies are not made or distributed for profit or commercial advantage and that copies bear this notice and the full citation on the first page. Copyrights for components of this work owned by others than the author(s) must be honored. Abstracting with credit is permitted. To copy otherwise, or republish, to post on servers or to redistribute to lists, requires prior specific permission and/or a fee. Copyright 2018 SBC.

IHC 2018, Anais Estendidos do XVII Simpósio Brasileiro sobre Fatores Humanos em Sistemas Computacionais

Outubro 22-26, 2018, Belém, Brasil

Competição de Avaliação - Graduação aplicativo para cuidados com ferimentos em idosos. Neste estudo, nove participantes idosos foram apresentados ao protótipo e participaram de uma entrevista semiestruturada. Um dos resultados obtidos foi a visão dos usuários sobre o aplicativo como um serviço adicional, que não substitui o serviço dos cuidadores. Além disso, os participantes concordaram que o uso do aplicativo pode reduzir as visitas médicas, mas sem impactar no contato humano. Em um estudo sistemático da literatura [4], foram encontrados 42 trabalhos publicados entre 2010 e 2014 que investigavam aplicativos relacionados a serviços de saúde. Das cinco categorias de trabalho levantadas, duas delas focavam em avaliação desses sistemas, totalizando 14 trabalhos.

Antes, era comum ver o uso de cadernos, tabelas e calendários para o acompanhamento do ciclo menstrual. Com a evolução da tecnologia, existem aplicativos capazes de desempenhar a mesma função, popularizando-se rapidamente e ganhando diversas versões. Os três aplicativos gratuitos mais populares nesta categoria na Google Play são: Meu Calendário $(\sim 4,5$ milhões de downloads), Clue ( $\sim 550$ mil downloads); e Flo ( 540 mil downloads). Mas será que esses aplicativos suprem as necessidades dos usuários?

Neste relatório, apresentamos os resultados de uma avaliação da usabilidade e experiência de uso em dois aplicativos de acompanhamento do ciclo menstrual (Clue e Meu Calendário), utilizando três técnicas/métodos: questionário online, diário de usuário e teste de usabilidade. O objetivo principal dos testes aplicados foi identificar problemas, tanto na interface, quanto na interação dos dois aplicativos avaliados. Após encontrar problemas, descobrir sua causa e o quanto isso prejudica o usuário, foram elaboradas sugestões de possíveis melhorias.

O restante do relatório está organizado da seguinte forma: na próxima seção apresentamos a metodologia, descrevendo os procedimentos adotados para cada técnica/método de avaliação; depois, apresentamos os resultados obtidos, organizados por ordem de realização da técnica; em seguida, apresentamos uma discussão dos resultados e uma seção de considerações finais.

\section{METODOLOGIA}

A fim de se obter resultados confiáveis e relevantes sobre a usabilidade e experiência de uso dos aplicativos de acompanhamento do ciclo menstrual, foram realizados

\footnotetext{
${ }^{1}$ https://play.google.com/store/search?q=ciclo $\% 20$ menstrual
} 
procedimentos metodológicos envolvendo várias técnicas de coleta e métodos de avaliação.

Conforme será visto adiante, por meio de um questionário online, identificamos os aplicativos de acompanhamento do ciclo menstrual mais populares entre os respondentes, definindo assim os aplicativos avaliados: Clue (utilizado por $61,6 \%$ dos 228 respondentes) e Meu Calendário (utilizado por 50,3\%). Antes de explicar as etapas da metodologia, apresentaremos os detalhes destes aplicativos.

\section{Aplicativos Avaliados}

Os aplicativos avaliados foram o Clue $^{2}$ e o Meu Calendário $^{3}$, que possuem funcionalidades semelhantes relacionadas ao acompanhamento do ciclo menstrual.

O Clue apresenta as seguintes funcionalidades: monitoramento do ciclo menstrual; lembretes sobre o próximo ciclo menstrual; Tensão Pré-Menstrual (TPM); período fértil e afins; rastreamento de sintomas como cólicas, emoções, alterações da pele, peso etc. Além disso, o aplicativo possui um algoritmo que aprende com as informações inseridas pelo usuário, deixando-as mais precisas e confiáveis de acordo com o uso. A Figura 1 (a) apresenta a tela de registros do Clue.

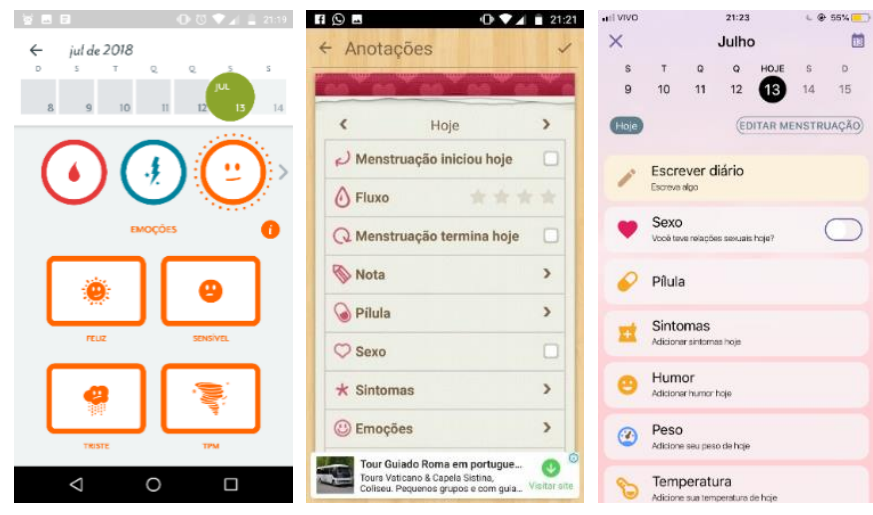

Figura 1. Clue (a) e Meu calendário (b-Android e c-iOS)

Em relação ao Meu Calendário, este oferece aos usuários: um calendário menstrual, possibilitando controlar os ciclos menstruais e a ovulação; lembretes de medicação; e informações sobre o período fértil. Foram avaliadas as versões para Android de ambos os aplicativos. No entanto, o aplicativo Meu Calendário também foi avaliado na versão para iOS, pois a interface era distinta, possuindo algumas funcionalidades extras. A Figura 1 (b e c) mostra as telas de registros do Meu Calendário para Android e iOS.

\section{Etapas da Pesquisa e Aplicação dos Métodos}

Nosso estudo foi elaborado a partir das seguintes técnicas de coletas e métodos de avaliação, em ordem de aplicação: questionário online, diários de usuário e teste de usabilidade, cujos procedimentos são detalhados a seguir.

\footnotetext{
${ }^{2}$ Versão 1.8 .0 atualizada em 30 de junho de 2018

${ }^{3}$ Android: Versão 1.645.182 atualizada em 23 de abril de 2018; iOS: Versão 5.0.1 atualizada em 30 de junho de 2018
}

Questionário

A primeira técnica aplicada foi um questionário online, com o objetivo de conhecer como os usuários lidam com a questão do acompanhamento do ciclo menstrual. $\mathrm{O}$ questionário foi organizado em algumas seções, como: caracterização do perfil (idade, gênero), formas de acompanhamento do ciclo menstrual (com aplicativos, em papel), motivações para acompanhar o ciclo, aplicativos e funcionalidades mais usadas.

Ao final do formulário, convidamos os respondentes a participarem das etapas seguintes da pesquisa, para isso, eles deveriam informar um email para contato posterior. $\mathrm{O}$ questionário foi disponibilizado em redes sociais e ficou disponível para preenchimento durante aproximadamente um mês. Um total de 228 usuários responderam.

\section{Diário de Usuário}

Durante a escolha dos métodos de avaliação, houve a necessidade de acompanhar de perto o uso do aplicativo pelo usuário. $\mathrm{O}$ contexto de uso específico de acompanhamento de ciclo menstrual cria a situação em que avaliar a usabilidade do sistema em apenas uma seção de teste não seria fidedigno ao seu uso natural. Isto acontece principalmente porque o usuário utiliza funções diferentes dos aplicativos no decorrer do ciclo e nos espaços de tempo que precedem ou que sucedem o referido período. Seria necessário um método que acompanhasse o usuário ao longo desse tempo de uso. Por isso, o Diário de Usuário foi incorporado aos nossos métodos de pesquisa.

Um diário é um documento criado por um indivíduo que mantém anotações regulares sobre eventos de suas vidas, enquanto eles ocorrem [10]. Com essa técnica, o usuário armazena relatos a cada vez que uma situação específica ocorre, podendo ser quando usar um determinado aplicativo, toda vez que ele se sentir confuso durante o uso ou até mesmo em um horário específico do dia. É importante existir uma periodicidade de armazenamento para que futuramente se possa comparar os dados. Diários são usados para registrar a existência e a quantidade de incidentes que acontecem com o usuário, podendo indicar a área de ocorrência e o motivo. A técnica do Diário foi utilizada em nossa pesquisa especialmente para avaliar aspectos da experiência de uso dos participantes.

Para definir os participantes do diário, foram utilizados os e-mails disponibilizados por aqueles que expressaram interesse em continuar participando da pesquisa, um total de 79 pessoas (entre eles, dois homens). No final, obtivemos 26 respostas positivas. Entretanto, apenas 11 pessoas (todas mulheres) participaram efetivamente da fase do Diário de Usuário, das quais apenas uma não tinha experiência com aplicativos de acompanhamento do ciclo menstrual. Entre as participantes, oito utilizaram o aplicativo Clue e três, o Meu Calendário.

Foram definidos dois tipos diferentes de diários: a cada uso do aplicativo, as participantes responderiam um diário 
resumido e, a cada semana, elas responderiam um diário completo. Assim, teríamos registros de suas atividades individualmente e um registro geral das atividades e reações da semana. A frequência de registro é algo importante no armazenamento de um diário. Para que os usuários não esquecessem (ou desistissem) de preencher os diários, semanalmente eram enviados lembretes sobre isso.

Para estruturar os registros, disponibilizamos um pequeno roteiro com perguntas a serem respondidas no registro diário e no registro semanal. No primeiro caso, os participantes respondiam às seguintes perguntas: 1) $\mathrm{O}$ que você queria fazer no App?; 2) Conseguiu fazer o que desejava? Se não, por quê?; 3) Como você se sentiu durante o uso? E depois? Já o registro semanal contava com as seguintes perguntas: 1) Quantas vezes você utilizou o App?; 2) Quais atividades você realizou?; 3) Você sentiu alguma facilidade ou dificuldade enquanto usava o aplicativo? Se sim, em qual parte?; 4) Você ficou satisfeito em relação ao uso do aplicativo?; 5) Você tem alguma sugestão para melhorar o uso do aplicativo? Se sim, qual?

As participantes ficaram livres para registrar o uso nos diários sempre que desejassem. Solicitamos que mantivessem o uso do aplicativo por pelo menos 20 dias, porém, elas tinham liberdade de informar ou não os dados durante esse período, conforme foi estabelecido no termo de consentimento. $\mathrm{O}$ material gerado poderia ser disponibilizado de três formas: pelo WhatsApp, pelo Telegram ou pelo Google Drive, conforme a preferência do usuário. Como forma de registro, elas poderiam produzir capturas da tela, registro por meio de texto e/ou áudio. Para organizar os relatos das participantes, planilhas e pastas individuais foram criadas no Google Drive. Para evitar constrangimentos, toda a comunicação com as participantes via WhatsApp e Telegram foi feita com as avaliadoras mulheres. Além disso, o material coletado foi disponibilizado nas pastas do Google Drive de forma anonimizada para o resto da equipe.

Ao final do período de teste, solicitamos às 11 participantes do diário que elas preenchessem um formulário online com perguntas sobre as funcionalidades mais usadas, as expectativas durante o uso, os pontos positivos e negativos do aplicativo, sugestões de melhoria, interesse em continuar usando o aplicativo e opinião sobre a experiência com o diário. Diante do tempo disponibilizado, uma das participantes acabou não respondendo.

\section{Teste de Usabilidade}

O último método de avaliação que utilizamos foi o teste de usabilidade, para o qual foi definido o seguinte perfil: pessoas em idade fértil que possuam familiaridade com o uso de aplicativos em geral (não necessariamente de acompanhamento de ciclo menstrual). O teste foi realizado com dez participantes, cinco homens e cinco mulheres, convidados por conveniência. Com o teste, buscamos levantar problemas de usabilidade nos sistemas Clue e Meu Calendário, sendo cinco usuários para cada aplicativo. Os usuários que realizaram o teste do Meu Calendário fizeram dois testes e duas entrevistas pós-teste, um no sistema operacional Android e outro no iOS, pois queríamos comparar a experiência de uso do usuário nos dois sistemas, já que este aplicativo tinha uma interface totalmente diferente nas duas versões (Figura 1).

Antes do teste efetivo, foram feitos dois testes pilotos, um para cada aplicativo, a fim de identificar erros no processo. Durante os pilotos, observamos problemas na apresentação do objetivo do teste, nas opções de resposta de algumas questões, no cenário de teste e na descrição de uma das tarefas, todos foram corrigidos para os testes oficiais.

Os testes duraram em média de 10 a 15 minutos. Foi utilizado um celular que não era do participante, com o aplicativo a ser avaliado e também um aplicativo de gravação de tela e áudio instalados.

O teste de usabilidade foi realizado seguindo-se algumas etapas. De início fizemos uma entrevista pré-teste com perguntas pessoais para entender com qual tipo de usuário estávamos lidando. Logo após, realizamos o teste de usabilidade em si e pedimos para que os usuários seguissem os cenários criados com dados pré-definidos, para evitar o possível constrangimento de o usuário ter que informar dados reais. Para cada perfil de usuário (homens e mulheres), foi criado um cenário diferente, mas com as mesmas tarefas. Para as mulheres, no cenário, a personagem era convidada a experimentar o acompanhamento do ciclo pelo aplicativo sugerido por uma amiga. No caso dos homens, no texto, o personagem já acompanhava o ciclo da namorada ou de uma parente, que passou a utilizar o aplicativo.

Para definir as tarefas a serem avaliadas, tomamos como base as principais funcionalidades que os aplicativos possuem, relatadas pelos respondentes do Questionário Online e, além disso, descritas na apresentação de cada aplicativo na versão Android e na versão IOS. Resumidamente, as tarefas solicitadas foram:

- $\quad$ Clue: 1) Inserir dados sobre o ciclo; 2) Verificar no calendário o próximo dia do ciclo e/ou dia fértil; 3) Fazer anotações sobre algum dia do calendário; 4) Selecionar análise de dor; 5) Adicionar lembrete de Menstruação atrasada; 6) Ativar opções de monitoramento sobre o ciclo; 7) Filtrar anotações para visualizar no calendário.

- Meu Calendário: 1) Inserir dados sobre o ciclo; 2) Verificar no calendário o próximo dia do ciclo e/ou dia fértil; 3) Fazer anotações sobre algum dia do calendário; 4) Verificar o relatório da cronologia; 5) Verificar o relatório da menstruação; 6) Verificar o relatório dos sintomas; 7) Adicionar lembrete de Inserir Menstruação; 8) Alterar a duração da menstruação; 9) Exportar documento para o médico; 10) Ativar opções de monitoramento sobre o ciclo. 
Por último, realizamos a entrevista pós-teste, para coletar informações sobre a experiência do usuário ao utilizar o aplicativo. A interação com os aplicativos foi gravada em vídeo e áudio e as entrevistas foram registradas em áudio.

\section{RESULTADOS}

Os resultados foram organizados de acordo com cada etapa da pesquisa, começando pelo questionário, seguido do diário e finalizando com o teste de usabilidade.

\section{Questionário}

Com o questionário, obtivemos 228 respostas. $95,2 \%$ dos participantes eram mulheres, $75,4 \%$ com idades entre $18 \mathrm{e}$ 24 anos e 53,5\% acompanhavam o ciclo menstrual.

Apenas 4,4\% (10) dos participantes eram homens. Apesar do baixo número, foi importante conhecer esse público. Eles afirmaram usar o aplicativo para acompanhar o ciclo das companheiras ou alguém da família. Também responderam um travesti e uma mulher transexual.

Em relação aos participantes da pesquisa que não acompanhavam o ciclo (12,3\%), os principais motivos mencionados foram falta de interesse, descuido, falta de tempo, preguiça ou distúrbios menstruais que impediam a regularidade do ciclo. Em relação à pergunta sobre situações que poderiam ter sido evitadas com o acompanhamento do ciclo menstrual, foram citadas, por exemplo, menstruação não esperada e gravidez. Uma resposta inesperada de um participante foi: "Saber quando não perturbar minhas irmãs". Os métodos de acompanhamento sem uso de aplicativos mais frequentes foram: memória $(52,6 \%)$, anotações $(33,3 \%)$ e tabelinha $(21,8 \%)$. Alguns respondentes mencionaram ainda a observação de sintomas corporais e o registro feito por outra pessoa. A maioria dos participantes afirmou acompanhar o ciclo de 1 a 5 anos.

Os aplicativos mais populares e consequentemente os mais utilizados foram o Clue (conhecido por 50,3\% e utilizado por $28,5 \%$ dos usuários) e o Meu Calendário (conhecido por $61,6 \%$ e utilizado por $30,5 \%$ dos usuários). A maioria dos usuários utilizava os aplicativos de 7 meses a 1 ano $(31,1 \%)$ e de 2 a 3 anos $(27,2 \%)$. Quando questionamos o porquê de utilizar aqueles aplicativos, a maioria respondeu: para acompanhar o ciclo, lembrar do anticoncepcional, por praticidade, por ser bonito e fácil de usar.

\section{Diário de Usuário}

O perfil das 11 participantes está detalhado na Tabela 1 . Sobre a faixa etária, apenas D4 tinha entre 25 e 29 anos, em relação à experiência prévia com aplicativos de acompanhamento de ciclo menstrual, apenas D3 nunca havia usado. A tabela também indicar o aplicativo utilizado durante o estudo com o Diário e a forma de registro.

Para a análise dos dados, todo o texto dos registros foi organizado em planilhas, de acordo com a data de registro de cada atividade. Após a observação e comparação dos dados, organizamos os resultados nas cinco categorias de análise detalhadas nas próximas subseções.

\begin{tabular}{r|l|l|l|l} 
ID & Idade & Experiência & Aplicativo & Registro \\
\hline D1 & $18-24$ & Flo & Clue & WA \\
D2 & $18-24$ & Clue, Maia e Flo & Clue & WA \\
D3 & $18-24$ & - & MC & WA \\
D4 & $25-29$ & Flo & MC & GD \\
D5 & $18-24$ & Clue & Clue & WA \\
D6 & $18-24$ & Maia & Clue & GD \\
D7 & $18-24$ & MC & Clue & WA \\
D8 & $18-24$ & Flo & Clue & WA \\
D9 & $18-24$ & Flo & Clue & WA \\
D10 & $18-24$ & Clue & MC & WA \\
D11 & $18-24$ & MC & Clue & TG \\
\hline
\end{tabular}

Legenda - MC: Meu Calendário | WA: WhatsApp | GD: Google Drive | TG: Telegram

Tabela 1. Perfil de participantes do Diário de Usuário

Quantidade de Registros e Intervalo de Participação

Observamos o nível e a forma de participação das pessoas.

Os dias de participação, levantados a partir das datas do primeiro dia de registro e do último dia de registro, variaram de 1 a 29 dias, distribuídos da seguinte forma: 4 participantes atuaram no estudo menos de 10 dias; 4 participantes, entre 10 e 19 dias; e 3 participantes permaneceram no estudo 20 dias ou mais. Além dos registros diários, 5 das 11 participantes (D2, D3, D6, D8, D9) fizeram o registro semanal pelo menos uma vez. A participante D11 foi a que teve menor atuação (usou o diário apenas uma vez), enquanto D2 forneceu um total de 8 registros. Apesar desses extremos, 8 das 11 participantes ficaram entre 3 e 5 registros. Observamos também a taxa de uso dos dias, ou seja, o quanto as participantes distribuíram os registros ao longo dos dias. Destacamos alguns casos especiais: D11 teve uma taxa alta $(1,00)$, mas que é pouco informativa, já que em um dia, ela fez um registro; D8 também apresentou uma alta taxa, mas mostrando muito mais eficiência (no intervalo de seis dias, ela realizou seis registros); D9, em dois dias de participação, realizou 4 registros (taxa de 2,00); D2, que participou durante mais dias teve também o maior número de registros (apesar de uma taxa baixa de uso). De qualquer forma, 7 das 11 participantes tiveram uma taxa menor que 0,50.

Outro dado importante é o "ritmo de participação", ou seja, saber se as participantes se mantiveram ativas durante os dias ou foram diminuindo a frequência de participação ao longo do tempo. Para isso, contabilizamos o intervalo entre os registros diários de cada participante. $\mathrm{O}$ resultado pode ser visto na Figura 2, que apresenta um gráfico ordenado por quantidade de dias de participação. Cada cor corresponde à quantidade de dias entre um registro e o próximo. Como é possível ver no gráfico, não identificamos um padrão no intervalo entre os registros ao longo dos dias. Por exemplo, entre o primeiro e o segundo registro (área vermelha), as pessoas levaram entre 1 e 11 dias; entre o terceiro e o quarto (área verde), levaram entre 2 e 15 dias. Já as poucas participantes que fizeram cinco registros (área 
laranja) levaram poucos dias para incluí-lo (entre 1 e 3 ). Pelo gráfico, é possível observar ainda usuários sem qualquer regularidade de registro (D7, D4, D5) e outros que apresentaram intervalos mais regulares (D8, D10, D2).

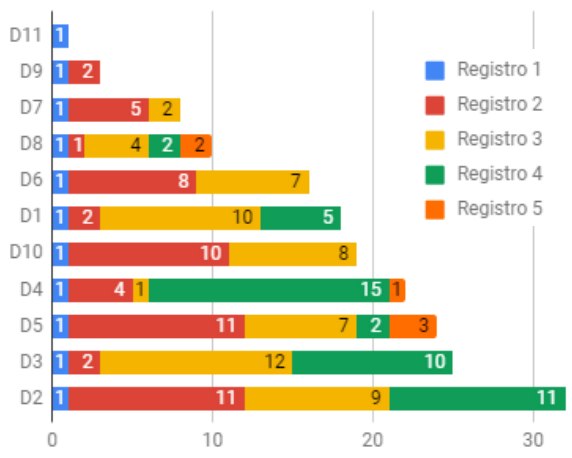

Figura 2. Intervalo entre registros

\section{Tarefas Realizadas}

Durante o período de uso do diário, as participantes realizaram algumas tarefas, escolhidas livremente, nos aplicativos Meu Calendário e Clue. Com os dados coletados, foi possível agrupar as tarefas mencionadas em seis grupos, conforme Tabela 2. Além destas, identificamos casos em que as participantes tentaram realizar tarefas que não estavam disponíveis nos aplicativos. A Tabela 2 mostra a quantidade de vezes que essas tarefas foram realizadas, separadas por aplicativo, além de informar o número de sucessos e insucessos ao tentar executá-las.

\begin{tabular}{|c|c|c|c|c|c|c|}
\hline & Tarefas & CL & MC & TT & $\mathbf{S}$ & $\mathbf{I}$ \\
\hline $\mathbf{1}$ & Conhecer o aplicativo & 4 & 2 & 6 & 6 & - \\
\hline 2 & Registrar o início do ciclo & 3 & 1 & 4 & 4 & - \\
\hline 3 & Realizar anotações & 8 & 5 & 13 & 13 & - \\
\hline 4 & Atualizar dados do ciclo & 5 & 2 & 7 & 5 & 2 \\
\hline 5 & Adicionar lembrete & 2 & - & 2 & 1 & 1 \\
\hline 6 & Analisar dados do ciclo & 10 & 1 & 11 & 11 & - \\
\hline 7 & Tarefas inexistentes & 2 & 1 & 3 & - & 3 \\
\hline
\end{tabular}

\section{Tabela 2. Tarefas realizadas durante o período de teste}

De modo geral, os resultados obtidos nas tarefas foram positivos: de seis insucessos, três se referiam a tarefas disponíveis no sistema (atualizar dados do ciclo e adicionar lembrete) e três foram decorrentes de tentativas de execução de tarefas inexistentes nos aplicativos. Em relação às tarefas realizadas individualmente, percebemos que apenas a participante D1 realizou quase todas as tarefas. As tarefas realizadas frequentemente por cada participante foram "realizar anotações" e "analisar dados do ciclo".

\section{Problemas Identificados}

Com a análise do conteúdo escrito pelas participantes, identificamos cinco problemas gerais: 1) inconveniências de interface, 2) ausência de funcionalidades, 3) erros, 4) dificuldade ao realizar registros e 5) outras dificuldades.

Em relação ao Clue, na categoria 1, três participantes acharam o layout "confuso", uma delas repetiu essa opinião duas vezes; uma participante achou a interface "feia"; e outra achou a interface "bagunçada". Na categoria 2, sete participantes sentiram falta de informações e funcionalidades, como notificação da próxima TPM, especificação do horário de anotações e registro de sintomas relacionados à pele; uma participante disse que o app tinha poucas opções para registro de emoções; três sentiram falta de receber notificações (lembretes de anotações, lembretes sobre). Em relação a este último, D6 relatou alto nível de preocupação com a gravidade do problema: "Também notei uma enorme falta em notificação. $O$ APP não me notificou que no dia [...] eu estaria no meu período fértil e tive relações sexuais sem proteção nenhuma, o que me deixa preocupada.". $\mathrm{Na}$ categoria 3, uma participante identificou erro no cálculo das datas; e outra relatou não ter conseguido alterar as informações do início do ciclo. Este problema trouxe como consequência o abandono do uso do aplicativo: "O fato é que não consegui mudar o dia do ciclo, então meio que não tô me baseando nele, e sim no outro aplicativo que eu já usava.". $\mathrm{Na}$ categoria 4, três participantes tiveram dificuldade no primeiro registro do aplicativo e uma, no registro dos sintomas. Na categoria 5, duas participantes acharam o calendário difícil de entender; quatro disseram haver muitas opções e informações; uma participante relatou que o aplicativo usava linguagem rebuscada; uma usuária teve dificuldades de encontrar os gráficos de acompanhamento; e uma teve dificuldade de colocar senha.

Em relação ao Meu Calendário, na categoria 1, apenas uma participante achou o layout "feio". Na categoria 2, uma participante relatou, duas vezes, que o aplicativo disponibiliza poucas opções para o registro de emoções. $\mathrm{Na}$ categoria 3, uma participante relatou, duas vezes, que houve erro no cálculo da data prevista para a ovulação. E, na categoria 5, uma participante relatou ter dificuldades para entender a linguagem "rebuscada" do aplicativo.

\section{Emoções e Sentimentos}

Dentro da análise de conteúdo realizada nos registros (diários e semanais) dos usuários, foi possível identificar como eles expressaram suas emoções e sentimentos durante a experiência de uso. Inicialmente analisamos o nível de satisfação dos usuários explicitamente revelado principalmente em tarefas específicas presentes no modelo do registro diário e no semanal. Considerando os registros diários, os resultados satisfatórios foram ligeiramente maiores que os insatisfatórios ( 27 x 22): sete participantes indicaram mais situações satisfatórias que insatisfatórias; e três, mais insatisfatórias que satisfatórias. Já em relação ao registro semanal, a diferença foi maior $(10 \times 1)$. Isto indica que, em alguns casos, apesar de haver "insatisfações" pontuais nos registros diários, as participantes, durante o registro semanal, fizeram uma avaliação mais geral.

Por meio da análise do conteúdo de todo o material textual disponibilizado pelas participantes, identificamos uma lista de 13 sentimentos positivos e 11 negativos expressos por 
elas, conforme listado abaixo, indicando entre parênteses a que aplicativo eles se referem e as ocorrências:

- Positivos: facilidade (CL: 11), segurança (CL:1), bemestar (MC: 4), surpresa (MC: 2), animação (MC: 1), êxito (CL: 7, MC: 1), tranquilidade (CL: 2, MC: 1), satisfação (CL: 4, MC: 4), superação (CL: 2, MC: 1), orientação (CL: 2), interesse (CL: 1), confiança (CL: 1), encantamento (CL: 1)

- Negativos: confusão (CL: 6), estranhamento (CL: 2), dúvida (CL: 1), frustração (CL: 3, MC: 1), fracasso (CL: 1, MC: 1), tédio (CL: 1), desorientação (CL: 2), irritação (CL: 1), indiferença (CL: 2), preocupação (CL: 1), insatisfação (CL: 1)

Em relação ao Clue, emoções positivas apareceram 32 vezes e negativas, 21, enquanto no Meu Calendário, as positivas ocorreram $14 \mathrm{e}$ as negativas, apenas duas vezes. Com o uso do Clue, o sentimento positivo mais mencionado foi a "facilidade" (11), seguido de "êxito" (7) e o sentimento negativo mais recorrente foi "confusão" (6), seguido de "frustração" (3). Em relação ao Meu Calendário, "bem-estar" e "satisfação" foram mencionados 4 vezes, e os únicos sentimentos negativos mencionados foram "frustração" e "fracasso" uma única vez cada.

\section{Questionário Após o Uso do Diário}

Após o período de teste dos aplicativos com o Diário de Usuário, dez das onze participantes responderam um questionário de feedback, ou seja, apenas uma participante optou por não responder o questionário.

As funcionalidades mais utilizadas, em ambos os aplicativos, foram "realizar anotações" e "analisar dados do ciclo". As expectativas da maioria das participantes, em relação a como seriam os sistemas, eram semelhantes. Sete participantes afirmaram que os aplicativos atingiram as suas expectativas e uma delas ressaltou que: "Saber esse conjunto de aspectos sobre o ciclo menstrual é importante para a saúde e bem-estar feminino no dia a dia.", pois as plataformas mostram que as mudanças que ocorrem no corpo (sintomas, alteração de humor, remédios) também interferem diretamente no ciclo menstrual.

Quanto aos pontos positivos, relataram que o Clue possui "textos informativos legais", a interface do sistema é limpa e disponibiliza diversas opções dentro de "registrar anotações". Em relação ao Meu Calendário, uma participante disse que "as funcionalidades são dinâmicas, pois é possivel atualizar como você se sente todos os dias". Já em relação aos pontos negativos, uma participante disse que o aplicativo Clue é "muito dependente de acesso", por ter precisado marcar o fluxo de sangramento todos os dias da menstruação e não somente o primeiro e último, para que o aplicativo identificasse que ela estava no período da menstruação, e outra disse que o aplicativo não anuncia a próxima menstruação com um alarme. Para o Meu Calendário, os pontos negativos relatados foram sobre linguagem rebuscada e interface confusa.
Em uma seção dedicada a sugestões sobre os aplicativos usados, uma das participantes relatou que o aplicativo Clue poderia se comunicar melhor com os usuários sobre o sucesso ou insucesso das ações: "Dar feedbacks de acordo com o que fazemos, por exemplo: quando colocamos o primeiro dia de menstruação, não conseguimos entender 'de primeira' que deu certo."

Sobre a continuação do uso dos aplicativos utilizados no diário, utilizamos uma escala com os seguintes valores: 1) "Com certeza, vou continuar usando"; 2) "Muito provável"; 3) "Não sei”; 4) "Pouco provável"; e 5) "Não vou continuar usando". Dez participantes responderam, das quais, duas que usaram o Clue afirmaram que com certeza continuarão usando o aplicativo, duas continuarão muito provavelmente, duas não sabem, uma talvez não use e outra não continuará usando. Em relação ao Meu Calendário, uma participante provavelmente continuará usando e uma não. Ou seja, a opinião foi bastante equilibrada entre elas, exatamente metade das oito do Clue demonstraram interesse em continuar usando, que foi o mesmo resultado para o $\mathrm{Meu}$ Calendário (uma usaria e uma não usaria).

\section{Teste de Usabilidade}

\section{Perfil dos Participantes}

A partir da entrevista pré-teste, foi possível conhecer o perfil dos participantes do Teste de usabilidade (Tabela 3).

Dos 10 participantes, um havia participado da etapa do Diário, porém, avaliando um aplicativo diferente. Três eram homens, todos tinham entre 20 e 24 anos e três não acompanhavam o ciclo menstrual. Em relação ao tempo de acompanhamento do ciclo, dois participantes começaram há menos de um ano e três deles há pelo menos cinco anos. Três participantes tinham experiência com aplicativos de acompanhamento de ciclo menstrual. Os participantes U1 a U5 realizaram o teste com o Clue e os demais (U6 a U10), com o Meu Calendário.

\begin{tabular}{|c|c|c|c|c|c|c|c|c|c|c|}
\hline & U1 & U2 & $\mathbf{U 3}$ & $\mathbf{U 4}$ & U5 & U6 & U7 & U8 & U9 & U10 \\
\hline Sexo & $\mathrm{F}$ & $\mathrm{F}$ & M & $\mathrm{F}$ & M & $\mathrm{F}$ & $\mathrm{F}$ & M & M & M \\
\hline Idade & 22 & 24 & 20 & 20 & 20 & 21 & 20 & 20 & 23 & 24 \\
\hline Acompanha & & $\mathrm{x}$ & & $\mathrm{x}$ & & $\mathrm{x}$ & $\mathrm{x}$ & $\mathrm{x}$ & & \\
\hline Tempo (anos) & & $>5$ & & 5 & & $?$ & $<1$ & $>5$ & & 1 \\
\hline Experiência & & & & $\mathrm{x}$ & & & $\mathrm{x}$ & $\mathrm{x}$ & & $\mathrm{X}$ \\
\hline Aplicativo & & & Clue & & & & $\mathrm{Meu}$ & $\mathrm{Ca}$ & ár & \\
\hline
\end{tabular}

Tabela 3. Perfil de participantes do Teste de Usabilidade

Em relação aos participantes que utilizaram o Clue, todos, exceto U1, tinham ensino superior incompleto. Entre as três mulheres, U1 não acompanhava o seu ciclo menstrual, por falta de interesse. Das que acompanhavam, U2 não utilizava aplicativos para isso e U4 utilizava exatamente o Clue. Já em relação aos participantes do Meu Calendário, todos, tinham ensino superior incompleto e todos, exceto U9, acompanhavam o ciclo menstrual. Entre os homens, U8 ajudava a tia no acompanhamento e U10 acompanhava junto com a namorada. U6 acompanha seu ciclo, mas não 
utiliza nenhum aplicativo para isso, devido a seu ciclo desregulado. Ela não informou há quanto tempo acompanha. U7, U9 e U10 acompanhavam o ciclo usando aplicativos diferentes do Meu Calendário.

\section{Tempo de Execução das Tarefas}

Durante a análise dos testes de usabilidade, o tempo gasto para a resolução das tarefas foi registrado, o que possibilitou o cálculo de uma Média e a Taxa de Sucesso na realização das tarefas, que corresponde à porcentagem dos usuários que obtiveram sucesso naquela atividade específica. Também foram registradas as situações em que o usuário não conseguiu resolver a tarefa (NC). A Tabela 4 mostra os dados de desempenho dos usuários do Clue.

Observando a tabela, apenas em dois casos os usuários não conseguiram realizar a tarefa: U5 não realizou T4 e U2 não realizou T6. A única tarefa que levou mais de dois minutos foi T1 realizada por U5, porque o usuário ficou confuso com as marcações no calendário e precisou de mais tempo para identificar o dia fértil e o período do ciclo menstrual.

\begin{tabular}{l|l|l|l|l|l|l|l} 
& U1 & U2 & U3 & U4 & U5 & Média & Sucesso \\
\hline T1 & $0: 37$ & $0: 36$ & $0: 16$ & $0: 25$ & $2: 40$ & $0: 54$ & $100 \%$ \\
T2 & $0: 57$ & $1: 08$ & $0: 43$ & $0: 53$ & $0: 52$ & $0: 54$ & $100 \%$ \\
T3 & $0: 10$ & $1: 50$ & $0: 32$ & $1: 07$ & $0: 43$ & $0: 52$ & $100 \%$ \\
T4 & $1: 06$ & $0: 30$ & $0: 32$ & $0: 52$ & NC & $0: 45$ & $80 \%$ \\
T5 & $1: 00$ & $0: 15$ & $0: 20$ & $1: 14$ & $0: 45$ & $0: 42$ & $100 \%$ \\
T6 & $1: 08$ & NC & $0: 52$ & $0: 38$ & $1: 06$ & $0: 55$ & $80 \%$
\end{tabular}

Tabela 4. Tempo das tarefas (Clue)

Em T4, os usuários teriam que ativar um lembrete de menstruação atrasada. Primeiramente, a opção que possibilita ativar o lembrete não é visível, estando junto com configurações e outras funções. Três usuários tiveram dificuldades para encontrar essa função e U5 não conseguiu encontrar. Outro problema foi a falta de feedback do sistema, o aplicativo solicita que o usuário escreva uma mensagem e o número de dias atrasados para ele notificar, porém, depois de tudo configurado, o sistema não retorna nenhuma mensagem de sucesso, deixando o usuário inseguro. Em T5, os usuários tinham que ativar opções de monitoramento sobre o ciclo, mas, por estarem na mesma seção dos lembretes, essas opções ficaram sem destaque. U4 teve dificuldade de encontrar a função e outro usuário afirmou estar confuso. Em T6, os usuários tinham que filtrar anotações para visualizar no calendário, que estava na tela de análise, onde se pode mudar a característica analisada. Porém, nada indica que aquela parte é clicável, por isso, U2 não conseguiu encontrá-la. Em resumo, os problemas do Clue foram causados pela falta de destaque nos elementos e falta de feedback.

Em relação ao Meu calendário, a Tabela 5 e a Tabela 6 apresentam o desempenho dos usuários nas versões Android e iOS, respectivamente. A T5 não estava disponível na versão Android.
Antes de comentar sobre os resultados, é importante esclarecer que o primeiro usuário testou a versão Android e depois a versão iOS. O segundo usuário fez o teste na ordem invertida, mas percebeu-se que o desempenho foi semelhante. Como pode ser visto nas tabelas, o número de problemas e insucessos no Android foi bem maior que na versão iOS. Assim, para reduzir o efeito da aprendizagem (já que eram as mesmas tarefas nas duas versões), decidiuse por manter a sequência para os demais participantes: primeiro iOS (por ser mais fácil), depois Android.

\begin{tabular}{l|l|l|l|l|l|l|l} 
& U6 & U7 & U8 & U9 & U10 & Média & Sucesso \\
\hline T1 & $1: 12$ & $0: 10$ & $1: 02$ & $0: 09$ & $0: 21$ & $0: 34$ & $100 \%$ \\
T2 & $6: 18$ & $0: 26$ & $0: 26$ & $1: 00$ & $0: 40$ & $1: 45$ & $100 \%$ \\
T3 & $4: 06$ & $0: 19$ & $1: 21$ & NC & $1: 07$ & $1: 43$ & $80 \%$ \\
T4 & $0: 11$ & $0: 41$ & $0: 32$ & $1: 42$ & $0: 15$ & $0: 39$ & $100 \%$ \\
T5 & - & - & - & - & - & - & - \\
T6 & NC & $0: 16$ & $0: 13$ & $0: 30$ & $1: 18$ & $0: 39$ & $80 \%$ \\
T7 & $2: 29$ & $0: 04$ & $0: 19$ & $0: 05$ & $0: 14$ & $0: 37$ & $100 \%$ \\
T8 & $0: 21$ & $0: 12$ & - & $0: 11$ & $1: 13$ & $0: 28$ & $100 \%$ \\
T9 & NC & $0: 22$ & $1: 56$ & $4: 26$ & $1: 57$ & $2: 10$ & $80 \%$
\end{tabular}

Tabela 5. Tempo das tarefas (Meu Calendário - Android)

\begin{tabular}{l|c|c|c|c|c|c|c} 
& U6 & U7 & U8 & U9 & U10 & Média & Sucesso \\
\hline T1 & $0: 18$ & $0: 41$ & $0: 53$ & $1: 03$ & $1: 05$ & $0: 48$ & $100 \%$ \\
T2 & $1: 30$ & $2: 28$ & $0: 31$ & $0: 50$ & $0: 42$ & $1: 12$ & $100 \%$ \\
T3 & $1: 40$ & $0: 19$ & $0: 04$ & $0: 18$ & $0: 23$ & $0: 32$ & $100 \%$ \\
T4 & $0: 04$ & $0: 04$ & $0: 05$ & $0: 03$ & $0: 06$ & $0: 04$ & $100 \%$ \\
T5 & $0: 03$ & $0: 04$ & $0: 03$ & $0: 03$ & $0: 05$ & $0: 03$ & $100 \%$ \\
T6 & $0: 06$ & $0: 15$ & $0: 20$ & $0: 21$ & $0: 21$ & $0: 16$ & $100 \%$ \\
T7 & $0: 28$ & $0: 15$ & $0: 13$ & $0: 16$ & $0: 17$ & $0: 17$ & $100 \%$ \\
T8 & $0: 07$ & $0: 07$ & $0: 04$ & $0: 24$ & $0: 24$ & $0: 13$ & $100 \%$ \\
T9 & NC & $1: 19$ & $0: 35$ & $0: 28$ & $1: 25$ & $0: 56$ & $80 \%$
\end{tabular}

Tabela 6. Tempo das tarefas (Meu Calendário - iOS)

Comparando-se as duas tabelas, é interessante perceber que, na versão Android, os usuários em geral passaram mais tempo para realizar as tarefas (todas as médias foram menores no iOS) e houve mais casos de insucesso (7 no Android e apenas 1 no iOS).

Especificamente sobre a versão Android, os usuários tiveram mais problemas nas tarefas 1, 3, 4, 6, 8 e 9. Em T1, os usuários tinham que verificar no calendário o próximo dia do ciclo e/ou dia fértil. U6 não conseguiu identificar os símbolos que se referiam a esses dias, não conseguindo ligar o sistema de símbolos e cores ao seu significado. U8 também teve dificuldade para encontrar e deduzir o significado dos símbolos. Em T2, U6 ficou confuso de como a anotação deveria ser feita, ao invés de marcar os ícones de sintomas, o usuário escreveu como uma nota. Porém, depois de resolver T3, ele conseguiu encontrar os ícones de sintomas e humor, finalizando a atividade do jeito certo, mas em um tempo bem maior que os outros usuários. Em T3, o usuário deveria verificar o relatório da cronologia. Três dos usuários tiveram dificuldade de encontrá-lo, pois não conseguiram ligar a imagem do ícone com o relatório da cronologia. Como consequência dessa 
dificuldade, U9 desistiu da atividade. Em T4, os usuários deveriam exibir o relatório da menstruação, mas U7 e U9 tiveram dificuldade em encontrar a função. Em T6, os usuários deveriam adicionar lembrete de inserir menstruação, função que fica entre as opções da seção de definições. U6 não conseguiu encontrar e desistiu da atividade. Em T8, os usuários deveriam exportar o documento para o médico. U8, talvez por um erro na execução do teste, acabou não realizando a tarefa (pulou o item na lista). Um usuário afirmou ter tido dificuldade para identificar e dois (U10 e U6) se sentiram confusos, porque quando o aplicativo vai enviar o e-mail para o médico, o Gmail é aberto automaticamente, porém não volta para o Meu Calendário. Em T9, os usuários deveriam ativar opções de monitoramento sobre o ciclo, que aparece na seção de definições com o nome de "Mostrar/ocultar opções", sem especificar quais são as opções e o que o usuário pode fazer. Por isso, U6 não conseguiu encontrar, e os quatro que encontraram tiveram dificuldade para achar. Ao olhar de um modo geral, os problemas detectados no Meu Calendário Android, são causados principalmente pela dificuldade de os usuários encontrarem as funções.

Mesmo tendo uma função a mais que o Android (T5), o iOS gerou problemas em apenas duas tarefas. Em T1, U9 e U10 se confundiram com as marcações e símbolos presentes no calendário, demorando mais tempo para associá-los ao dia fértil e período menstrual. Em T9, U6 e U7 sentiram dificuldade para encontrar as opções de monitoramento e U6 acabou desistindo da atividade. Vê-se, portanto, que os usuários tiveram mais sucesso ao usar a versão iOS do Meu Calendário, quando comparada à versão Android.

\section{Quantidade e Gravidade dos Erros}

Outra métrica importante no teste de usabilidade é a quantidade de erros enfrentados pelos participantes, independente se eles concluíram ou não as tarefas. Para cada aplicativo testado, identificamos o número de erros e identificamos através de um código de cores os níveis de sucesso na interação de cada pessoa com o sistema.

A Tabela 7 apresenta a quantidade de erros que os usuários cometeram até localizar e concluir cada tarefa. As cores representam o que cada usuário fez, conforme a legenda.

Observando-se a tabela, vê-se que a maior quantidade de erros ocorreu na versão Android do Meu Calendário, totalizando 52, enquanto o mesmo aplicativo no $\mathrm{iOS}$ gerou 25 erros e o Clue, 37. Focando os números por participante, vê-se que cinco deles cometeram até 5 erros; seis participantes, entre 6 e 10 erros; e quatro participantes cometeram mais de 10 erros. Neste último grupo, 3 dos 5 eram participantes do Meu Calendário Android.

Relacionando esses dados com o perfil dos usuários (Tabela 3), vê-se que, em relação ao primeiro grupo (com menos erros), 4 participantes já tinham usado aplicativos semelhantes e um não usava (U9), entre eles, a U4 já havia utilizado o Clue. Curiosamente, U9, que não tinha experiência com aplicativos de acompanhamento de ciclo, foi o participante que menos cometeu erros (apenas um na versão iOS) e o que mais cometeu erros (15 no Android), o que ilustra a discrepância entre as duas versões. Já em relação ao segundo grupo (com quantidade intermediária de erros), somente U7 já utilizava algum aplicativo de ciclo menstrual. Finalmente, para o último grupo, U6 nunca tinha utilizado nenhum aplicativo deste tipo, o que pode explicar o alto número de erros nas duas versões testadas. Já os outros dois usuários, U10 utilizava outro aplicativo para acompanhar o ciclo da namorada e U9 não tinha experiência com esse tipo de aplicativo.

\section{\begin{tabular}{llllllllllll} 
T1 & T2 & T3 & T4 & T5 & T6 & T7 & T8 & T9 & TT \\
\hline
\end{tabular}}

\begin{tabular}{|c|c|c|c|c|c|c|c|c|c|c|c|}
\hline \multirow{6}{*}{ 气 } & & & & & & & & & & & \\
\hline & U1 & 2 & 1 & 0 & 2 & 3 & 1 & & & & 9 \\
\hline & U2 & 2 & 1 & 0 & 3 & 0 & 3 & & & & 9 \\
\hline & U3 & 0 & 1 & 3 & 1 & 2 & 1 & & & & 8 \\
\hline & U4 & 0 & 0 & 0 & 0 & 0 & 2 & & & & 2 \\
\hline & U5 & 2 & 1 & 1 & 3 & 1 & 1 & & & & 9 \\
\hline \multirow{5}{*}{ 党 } & U6 & 0 & 2 & 2 & 0 & - & 0 & 3 & 0 & 4 & 11 \\
\hline & U7 & 0 & 0 & 1 & 2 & - & 0 & 0 & 0 & 0 & 3 \\
\hline & U8 & 0 & 0 & 3 & 1 & - & 0 & 0 & - & 5 & 9 \\
\hline & U9 & 1 & 1 & 3 & 4 & - & 0 & 0 & 0 & 6 & 15 \\
\hline & U10 & 1 & 0 & 3 & 2 & - & 0 & 0 & 2 & 6 & 14 \\
\hline \multirow{5}{*}{${ }^{\cup} \stackrel{0}{2}$} & U6 & 0 & 2 & 3 & 0 & 0 & 0 & 1 & 0 & 4 & 10 \\
\hline & U7 & 1 & 0 & 1 & 0 & 0 & 0 & 0 & 0 & 4 & 6 \\
\hline & U8 & 0 & 0 & 0 & 0 & 0 & 0 & 0 & 1 & 4 & 5 \\
\hline & U9 & 0 & 0 & 0 & 0 & 0 & 0 & 0 & 0 & 1 & 1 \\
\hline & U10 & 1 & 0 & 0 & 0 & 0 & 1 & 0 & 0 & 1 & 3 \\
\hline
\end{tabular}

Legenda

\begin{tabular}{l|l|l|}
\hline Concluído & Concluído depois & Concluído com ajuda \\
Concluído com dificuldade & Não concluído & Desistiu \\
\hline
\end{tabular}

Tabela 7. Erros cometidos durante a realização das tarefas

Ao analisar a tabela de erro referente ao aplicativo $\mathrm{Meu}$ Calendário, podemos ver que a versão Android mostra-se mais problemática em comparação ao iOS. Segundo os comentários dos usuários, a versão do iOS mostrou-se ser mais limpa e fácil de usar, e fica nítida a facilidade que eles tiveram em usar o sistema, já que foram poucos erros e insucessos. Ainda assim, notou-se uma maior dificuldade na T9, nas duas versões do aplicativo. Os usuários disseram que não ficou claro onde eles poderiam achar a opção, além de muitos relatarem não saber para o que servia.

Focando nos dados da versão Android, vê-se que a taxa de erros foi muito maior, existiram vários problemas durante o uso. Além da T9, já comentada acima, a outra tarefa mais problemática foi a T3, que, segundo os usuários, estava em um local muito escondido e difícil de achar. Vale lembrar que o sistema Android foi utilizado depois do iOS pelos usuários, com exceção da U6, mesmo assim os usuários tiveram mais problemas e reclamações no Android.

\section{Entrevista Pós-teste}

Em relação à experiência com o Clue, os usuários comentaram sobre a falta de organização na interface, que tinha excesso de funções. Por conta dessa complexidade, alguns consideraram que o aplicativo era pouco intuitivo e difícil para usuários iniciantes. Um usuário até afirmou que 
trocou o Clue por um aplicativo mais simples. Sobre estar satisfeito ou não após o uso, os usuários ficaram divididos. Os que afirmaram estarem insatisfeitos ressaltaram que o aplicativo não era fácil de compreender, além de não conseguirem encontrar o que procuravam. Outros usuários não conseguiram entender nem mesmo o funcionamento do aplicativo, assim, não conseguiram decidir se estavam satisfeitos ou não. Sobre as dúvidas no sistema, eles destacaram os símbolos de nuvens e manchas no calendário que eram difíceis de encontrar e entender. Também acharam confusa a seção de filtrar as análises e adicionar lembretes. Dentre as sugestões de melhoria, eles afirmaram que era preciso simplificar as telas para que ele fique mais fácil de entender, além de precisar de um tutorial inicial apresentando suas funções. Também seria importante simplificar e explicar melhor as funções de adicionar lembrete e fazer análise. As opções de marcar e desmarcar as informações deveriam aparecer no começo do aplicativo para que o usuário pudesse entender o que estaria sendo exibido. O aplicativo também deveria explicar sobre os lembretes ativos ou deixá-los desativados. Além disso, os usuários achariam útil apresentar como o aplicativo consegue prever as situações que acontecerão, como cólicas e fluxo de sangramento, e como algumas opções de monitoramento interferem na análise.

Em relação ao Meu Calendário, no teste feito no Android, a opinião dos usuários foi quase unânime em questão à satisfação de uso, 4 de 5 usuários reclamaram sobre muitos pontos do aplicativo: falta de organização, navegação complicada, categorização "ruim e nada intuitiva", "design horroroso" e pouco atrativo. Já sobre a versão iOS, a opinião foi totalmente oposta: 4 de 5 usuários tiveram facilidade de usar o sistema, e um usuário, mesmo não tendo dificuldade, não gostou do aplicativo. Dois usuários relataram um problema de entendimento ao tentar achar o período do ciclo. Todos os usuários relataram insatisfação de uso no sistema Android, especialmente em relação aos relatórios, às opções de monitoramento e às partes clicáveis no sistema. No iOS, os usuários disseram não ter tantos problemas, a não ser nas opções de monitoramento, que também era um problema no sistema Android. Além disso, um usuário relatou a dificuldade de entender a parte do ciclo. Quando perguntamos se existia alguma dúvida sobre o sistema, três usuários disseram que não entenderam para quê servia a opção de ativar opções de monitoramento, três não gostaram da tentativa do sistema em "ser fofinho", com o gatinho na tela inicial. Outro problema relatado, mas que não foi pedido como atividade, foi o gráfico, o usuário relatou que tentou consulta-lo, mas acabou não entendendo nada. Já sobre o iOS, não relataram muitos problemas de entendimento no sistema, só duas pessoas mencionaram alguns problemas nos ícones, afirmando que poderiam ser mais intuitivos. Em relação às dificuldades que o usuário teve ao utilizar o sistema no Android, todos consideraram difícil ver os relatórios e as opções de monitoramento, um usuário disse que teve problemas em entender sobre exportação de documentos e informações nos relatórios. Diferente do Android, o iOS não gerou quase nenhuma dificuldade, a não ser a opção de monitoramento, que era similar à versão no Android. Alguns usuários relataram a facilidade de encontrar os relatórios no iOS, ponto que foi de maior dificuldade no Android. Todos os usuários que opinaram sobre uma melhoria do sistema Android, foi para que melhorassem a categorização do sistema, deixando opções importantes e relevantes mais visíveis, que deixasse a interface mais simples e limpa. Um dos usuários sugeriu que o aplicativo fosse completamente refeito, pois existiam muitos problemas. Já no iOS, o nível de satisfação com o sistema foi muito mais elevado, o único ponto que falaram sobre melhorias seria juntar algumas informações, como a opção de monitoramento ao calendário, pois essas duas funções são interligadas. Um usuário também sugeriu diminuir a quantidade de telas.

\section{DISCUSSÃO}

O uso combinado de diferentes técnicas e métodos de avaliação permitiu a obtenção de resultados ricos e relevantes a respeito do contexto de uso, da usabilidade e da experiência de uso dos aplicativos de monitoramento do ciclo menstrual.

O questionário online permitiu conhecer as motivações de se acompanhar ou não o ciclo menstrual. Descobrimos que muitos respondentes alegaram preguiça, desinteresse ou falta de tempo para acompanhar o ciclo. Assim, os designers desse tipo de aplicativo devem se esforçar em deixar o uso dos aplicativos ainda mais facilitado para atrair esse público. No questionário, também se mencionou consequências ruins da ausência de acompanhamento, como menstruação inesperada e gravidez indesejada. Talvez o resultado mais interessante do questionário foi perceber a existência de usuários homens, mesmo que uma pequena parcela. Isso mostra que, apesar de o ciclo menstrual ser um fenômeno exclusivamente feminino, há interesse por parte de alguns homens em acompanhar o ciclo de algumas mulheres com as quais eles convivem. Mais uma vez, este é um "recado" importante para os designers, que devem estar atentos em incluir este perfil em seu público-alvo, oferecendo funcionalidades em grupo, ou seja, o ciclo de uma determinada usuária ser acompanhado por ela e por outras pessoas.

Em relação ao Diário de Usuário, percebemos que essa técnica foi fundamental para entendermos como era a experiência de uso das participantes em contexto real, durante boa parte do período do ciclo menstrual. Como resultados, vimos que, em geral, as participantes foram bem-sucedidas nas tarefas realizadas, apesar de, em algumas ocasiões, demonstrarem insatisfação e outros sentimentos negativos, além de estarem sempre dispostas a sugerir melhorias. Os registros disponibilizados foram importantes para identificar problemas nos sistemas avaliados e suas consequências. Algumas participantes relataram não confiar nos cálculos dos aplicativos para as 
previsões do ciclo (próxima menstruação, dia fértil etc.). Por conta disso, uma delas manteve o acompanhamento em outro aplicativo com o qual já estava habituada. Outro relato revelador foi a frustração e preocupação de uma participante que alegou ter mantido relações sexuais sem proteção, sem saber que estava em seu período fértil, já que o aplicativo não a notificou. Este dado revela inclusive um estado de dependência da participante com este tipo de tecnologia, ou seja, algo tão sério como uma gravidez indesejada poderia acontecer por conta da presença ou ausência de uma funcionalidade no aplicativo.

O uso da técnica de Diário de Usuário apresentou-se desafiadora. O ideal seria ter contado com a participação das pessoas durante vários meses, o que não foi possível durante o nosso estudo. Outro problema é a questão do engajamento das participantes. Vimos que houve uma grande variação no número e frequência de registros e que o maior número de dias de participação não necessariamente significava maior quantidade de registros. Já conscientes desta possibilidade, os avaliadores adotaram a estratégia de enviar lembretes semanais solicitando a realização dos registros. Foi interessante também tirar proveito das formas de comunicação às quais as participantes estavam habituadas (WhatsApp, Telegram e Google Drive) para coletar o material do diário.

Já em relação ao Teste de Usabilidade, por ser um método de avaliação controlado, conseguiu-se avaliar um conjunto de tarefas mais abrangente que no Diário. Além disso, pode-se envolver alguns homens na avaliação e conhecer sobre suas experiências de uso. Em relação ao aplicativo Clue, percebeu-se que as pessoas que conseguiam concluir as tarefas facilmente se movimentavam entre as telas mais pela intuição e/ou experiência prévia do que por uma boa usabilidade do sistema. Em alguns casos, esta dificuldade gerou situações em que usuários se perdiam facilmente, não conseguindo achar os locais para onde eles deveriam ir, ou identificar uma informação na tela. Assim, o sistema não se mostrou intuitivo e amigável ao primeiro uso, deixando vários usuários confusos e insatisfeitos.

Em relação ao aplicativo Meu Calendário, o resultado mais relevante foi a discrepância entre as duas versões (Android e IOS). Enquanto na Android, os usuários tiveram dificuldade para encontrar as funções do aplicativo, notouse que, na versão do iOS, os usuários conseguiam encontrar e concluir as tarefas mais rapidamente e tiveram menos desistências. Os usuários realizaram as mesmas tarefas nos dois aplicativos (com exceção da T5, disponível apenas em iOS), porém eles se sentiram muito mais satisfeitos ao usar o aplicativo no iOS do que no Android.

\section{CONSIDERAÇÕES FINAIS}

Os aplicativos avaliados beneficiam diversos usuários, pois funcionando como método de registro e acompanhamento do ciclo menstrual. As informações são úteis para manter as mulheres mais conscientes do seu próprio corpo, auxiliando-as no acompanhamento de sintomas e datas, além de apoiarem no planejamento da fertilidade, ajudando a quem quer e a quem não quer engravidar.

A avaliação realizada com o Clue e o Meu calendário revelou que eles têm funcionalidades semelhantes, mas geram experiências de uso muito diversas, evidenciadas principalmente pelo Teste de Usabilidade que mostrou como a versão para o iOS era melhor que a do Android.

A aplicação do questionário, do diário e do teste de usabilidade possibilitou uma análise mais abrangente sobre a usabilidade e experiência de uso dos aplicativos avaliados. Foram diferentes fenômenos, formatos e focos investigados. Através de uma abordagem mista de pesquisa [5], com a análise de dados quantitativos e qualitativos nas três técnicas, pudemos conhecer melhor os meandros, problemas e possibilidades dos aplicativos para acompanhamento do ciclo menstrual.

Acreditamos que este relatório pode contribuir em duas vertentes: ao apresentar uma metodologia rica de avaliação, que pode ser replicada e reaproveitada em outros contextos semelhantes, e ao apresentar os problemas e sugestões de melhoria para os aplicativos avaliados, que podem ser úteis para designers de aplicativos deste tipo.

\section{REFERÊNCIAS}

1. Kate Bennett, Floriana Grasso, Victoria Lowers, Alison McKay, Christine Milligan. 2015. Evaluation of an App to Support Older Adults with Wounds. In Proc. of $\mathrm{DH}$ '15. ACM.

2. John W. Creswell, Vicki L. P. Clark. 2017. Designing and conducting mixed methods research. Sage publications.

3. Dmitri Katz, Eirik Arsand, Nick Dalton, Simon Holland, Clare Martin, Carl M. Olsson, and Blaine A. Price. 2016. Designing, developing, and evaluating the future internet of personal health. In Proc. of UbiComp '16. ACM.

4. Henna Kim, Bo Xie. 2015. Health literacy and internet- and mobile app-based health services: a systematic review of the literature. In Proc. of ASIST '15. American Society for Information Science, Silver Springs, Article 75.

5. Jonathan Lazar, Jinjuan Heidi Feng Harry Hochheiser. 2010. Research Methods in human-computer interaction. WILEY, West Sussex, UK.

6. Claudia D. Roquet and Corina Sas. 2018. Evaluating Mindfulness Meditation Apps. In Extended Abstracts of CHI EA '18. ACM.

7. Wally Smith, Greg Wadley, Oliver Daly, Marianne Webb, Jo Hughson, John Hajek, Anna Parker, Robyn Woodward-Kron, and David Story. 2017. Designing an app for pregnancy care for a culturally and linguistically diverse community. In Proc. of OZCHI '17. ACM. 